\title{
Structural, Electronic, and Catalytic Modulation of Chelating Pyridylideneamide Ruthenium(II) Complexes
}

\author{
Miquel Navarro, ${ }^{\dagger}$ Candela Segarra,${ }^{\dagger}$ Tim Pfister, ${ }^{\dagger}$ Martin Albrecht* ${ }^{\dagger}$ \\ ${ }^{\dagger}$ Department of Chemistry and Biochemistry, University of Bern, Freiestrasse 3, CH-3012 Bern, \\ Switzerland. \\ E-mail: martin.albrecht@dcb.unibe.ch
}

\begin{abstract}
A family of $\mathrm{Ru}(\mathrm{cym})$-type complexes bearing different pyridylideneamide (PYA) ligands has been prepared. Incorporation of diverse potentially coordinating sites afforded a series of different chelating hybrid ligands containing a PYA nitrogen as one donor site and a second variable donor site constituted of a cyclometallated aryl ring (complex 3a), a pyridine (3b), a pyridylidene (3c), another PYA unit (3d), or a triazolylidene ligand (3e). Structural and electrochemical analyses indicate considerable electronic variation in this series with decreasing donor ability from phenyl $>$ PYA $\sim$ triazolylidene $>$ pyridylidene $>$ pyridine. This trend allows the electronic properties of the metal center to be tailored, and reveals the strong donor properties of PYA ligands, surpassing those of pyridine-derived N-heterocyclic carbenes. The impact of these tunable donor properties was demonstrated in transfer hydrogenation catalysis, for which a direct correlation between donor properties and catalytic activity was established.
\end{abstract}

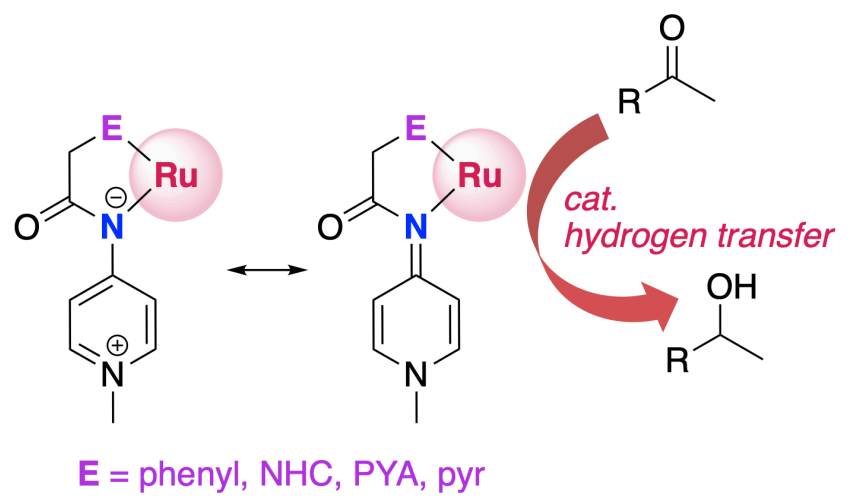




\section{Introduction}

Pyridylideneamides (PYAs) are a relatively new class of nitrogen donor ligands, which display remarkable electronic flexibility and strong $\sigma$ donor properties. These features are similar to those of Nheterocyclic carbenes (NHCs), ${ }^{1}$ and pyridylidene amines (PYEs). ${ }^{2}$ Their donor flexibility arises from potential coordination to the metal center as a $\pi$-acidic imine with formally neutral (L-type) donor properties, or as a $\pi$-basic zwitterionic pyridinium amide (X-type donor). This electronic flexibility is illustrated by the two limiting resonance forms of PYA ligands (Fig. 1a): the neutral imine resonance structure $\mathbf{A}$ features a dearomatized heterocycle and a diene type structure with an exocyclic $\mathrm{C}=\mathrm{N} \pi$ bond, while the zwitterionic resonance structure $\mathbf{B}$ features a formally anionic $\pi$ donor ligating amide and an aromatic resonance-stabilized heterocycle. We recently demonstrated the adaptiveness of this ligand in response to the external environment, such as solvent polarity that enhances the relevance of either resonance structure A (apolar solvents) or B (polar solvents), and exploited this donor flexibility to enhance ruthenium-catalyzed transfer hydrogenation ${ }^{3}$ and olefin oxidation. ${ }^{4}$ Furthermore, this electronic flexibility was used to prepare a series of iridium complexes with phenyl-substituted PYA ligands to increase the efficiency of the iridium center in water oxidation catalysis, transfer hydrogenation of ketones and imines, and the hydrosilylation of alkenes. ${ }^{5}$

a)

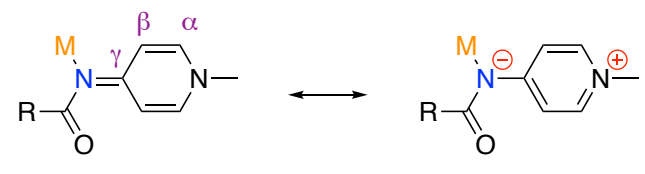

A

B

b)

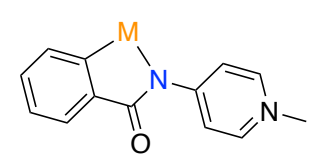<smiles></smiles><smiles></smiles><smiles></smiles><smiles></smiles>

Figure 1. a) Generic representation of pyridylidene amide ligands (PYA) and their limiting neutral (A) and zwitterionic (B) resonance structures; b) PYA ligand containing a chelating group (C).

The straightforward synthesis of PYA ligands provides access to vast opportunities for ligand modifications as a methodology to fine-tune electronic and steric properties of the coordinated metal center for improved catalytic activity. ${ }^{6}$ Herein, we have applied this concept to introduce different chelating groups to the PYA ligand core. Chelating groups have been selected which vary the electronic properties of the metal center significantly without altering the steric impact considerably. To this end, 
different arene ligands were introduced to the PYA scaffold (Figure 1b), including phenyl (as strictly anionic ligand), pyridyl (as strictly neutral donor ligand), mesoionic carbenes (triazolylidenes and 3pyridylidenes as formally neutral ligands with strong donor properties), and PYA ligands (as a bis-PYA ligand to enhance the electronic flexibility of the bidentate ligand). Of note the phenyl, pyridyl, and pyridylidene co-ligand all feature a 6-membered aromatic ring as chelating group with essentially no steric divergence. The triazolylidene unit with two methyl substituents is sterically almost identical to the pyridyl unit. ${ }^{3 b}$ Hence, the selected ligand structures have minimal steric variation, but are expected to differ considerably in their electronic donor properties. Structural and electronic studies on the chelating ruthenium complexes provided insights into the effective donor properties of the PYA chelates. Moreover, application of these complexes in transfer hydrogenation catalysis reveals a direct correlation between donor strength of the chelate ligand and the ruthenium-centered catalytic activity.

\section{Results and discussion}

Synthesis. The phenyl-PYA ruthenium complex 3a was prepared starting from pyridylamide 1a via the known $^{7}$ pyridinium salt 2a (Scheme 1). Deprotonation of 2a with aqueous $\mathrm{NaOH}$ followed by reaction with $\left[\mathrm{RuCl}_{2}(\mathrm{cym})\right]_{2}$ in the presence of $\mathrm{NaOAc}$ as additive ${ }^{8}$ induced cyclometallation (cym $=p$-cymene; Scheme 1) and afforded complex 3a in a moderate $61 \%$ yield. The complex is completely air-stable and was purified by standard column chromatography on silica. Coordination of the ligand to the Ru center was confirmed by the splitting of the aromatic cymene protons into four distinct doublets between 5.3 and $4.9 \mathrm{ppm}$ in the ${ }^{1} \mathrm{H}$ NMR spectrum due to the loss of symmetry, as well as by the ${ }^{13} \mathrm{C}$ resonance of the amide carbonyl $\left(\delta_{\mathrm{C}}=180.8\right)$, which appears at lower field than in the free ligand $\left(\delta_{\mathrm{C}}=176.5\right)$ and indicates coordination of the amide to the metal center. ${ }^{9}$ Cyclometallation was also confirmed spectroscopically by the presence of only four phenyl proton signals in the aromatic region of the ${ }^{1} \mathrm{H}$ NMR spectrum.

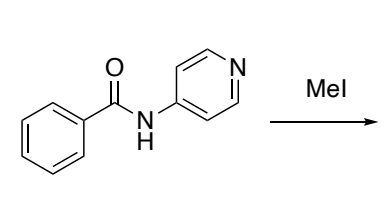

$1 \mathbf{a}$

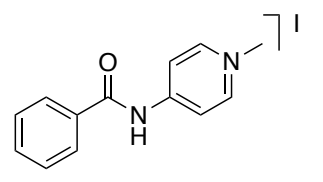

$2 a$

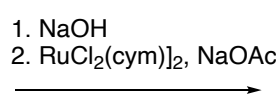

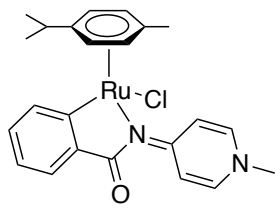

$3 a$

Scheme 1. Synthesis of ruthenium complex 3a.

Modification of the chelating unit in the PYA ligand was readily achieved by starting the ligand synthesis from picolinic acid instead of benzoic acid. Amidation was accomplished via formation of picolinoyl chloride and condensation with 4-aminopyridine in the presence of $\mathrm{NEt}_{3}$, which yielded the amide $\mathbf{1 b}$ in good yield (Scheme 2) ${ }^{9 b, 10}$ Alkylation of $\mathbf{1 b}$ with 1 mol equiv of MeI afforded the iodide analogue of the monomethylated pyridinium salt $\mathbf{2 b}$ Even when a large excess of MeI was used, the 
monoalkylated pyridinium salt was obtained selectively, indicating substantial electronic differences of the two pyridyl heterocycles in $\mathbf{1 b}$ imparted by the electron-donating $\mathrm{NR}_{2}$ group $v s$ an electronwithdrawing $\mathrm{C}(=\mathrm{O}) \mathrm{R}$ substituent. They also suggest that $\mathrm{MeI}$ is not a sufficiently strongly alkylating agent to methylate both pyridyl rings.

When exposing the dipyridiyl compound $\mathbf{1 b}$ to MeOTf as a stronger alkylating agent than MeI, the known $^{10 a}$ pyridinium salt $\mathbf{2 b}$ only formed selectively when the reaction was performed at low temperature $\left(0^{\circ} \mathrm{C}\right)$ and with stoichiometric quantities of MeOTf. The use of more than one equivalent of MeOTf gave a mixture of mono- and dimethylated products. Optimization of the reaction conditions to elevated temperatures (refluxing 1,2-dichlorethane) and a large excess of MeOTf (10 equiv) yielded the dimethylated salt $2 \mathbf{c}$ selectively. Formation of compound $\mathbf{2 c}$ was confirmed by the appearance of two singlets at 4.45 and $4.27 \mathrm{ppm}$ corresponding to the two different $\mathrm{NCH}_{3}$ groups in the ${ }^{1} \mathrm{H}$ NMR spectrum as well as the deshielding of the $\mathrm{C}_{\mathrm{pyr}}-\mathrm{H}$ proton resonances. In addition, salt $\mathbf{2 c}$ showed a characteristic $[\mathrm{M}-2 \mathrm{OTf}]^{2+} \mathrm{m} / \mathrm{z}$ signal at $114.5599 \mathrm{amu}$ (theoretical value $114.5602 \mathrm{amu}$ ) in high resolution MS.

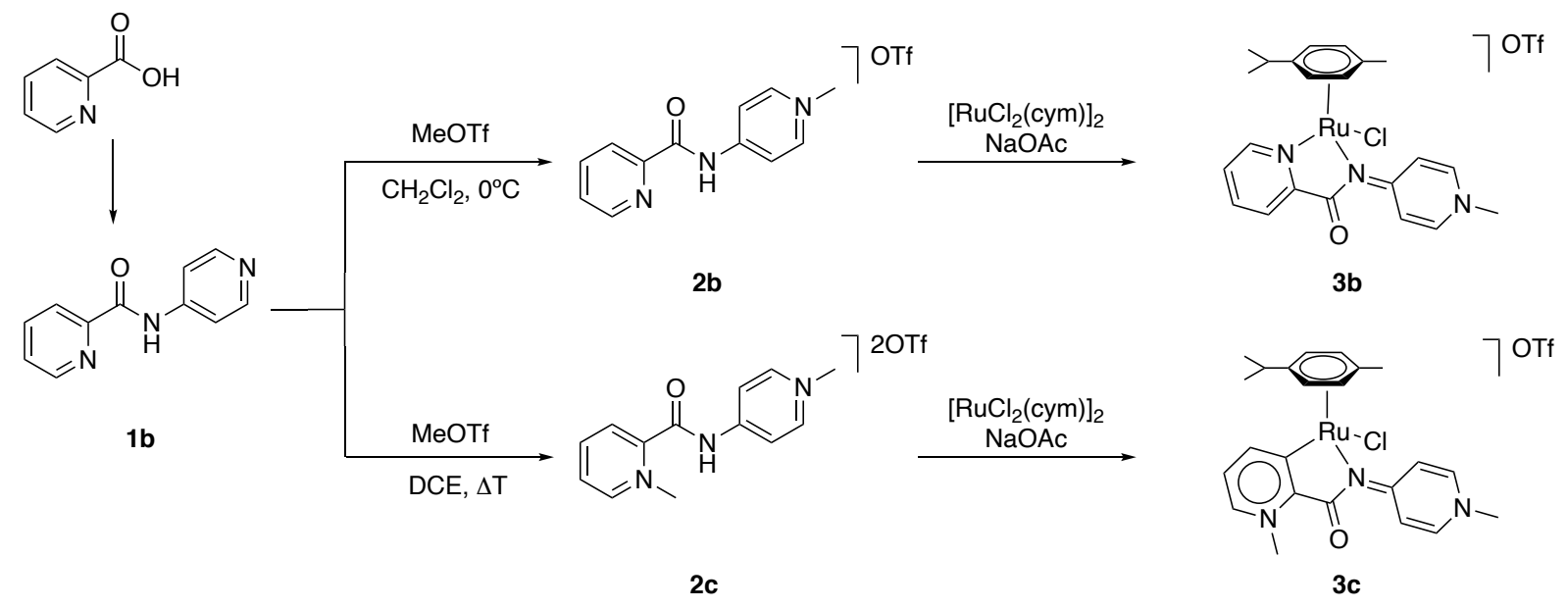

Scheme 2. Synthesis of ruthenium PYA complexes $\mathbf{3 b}$ and $\mathbf{3 c}$.

All attempts to obtain the corresponding free ligands by deprotonation of the amide with different bases have been unsuccessful and therefore the deprotonation reaction was performed in situ in the presence of the metal precursor. The reaction of pyridinium salt $\mathbf{2} \mathbf{b}$ with $\left[\mathrm{RuCl}_{2}(\mathrm{cym})\right]_{2}$ and an excess of $\mathrm{NaOAc}$ yielded complex 3b with a N,N-bidentate chelating PYA-pyridyl ligand. Formation of the ruthenium complex was established by the disappearance of the amide $\mathrm{NH}$ proton, as well as the characteristic downfield shift of the $\mathrm{H}_{\mathrm{pyr}}$ in ortho position to the pyridine nitrogen from $8.59 \mathrm{ppm}$ in the free ligand to $9.04 \mathrm{ppm}$ in complex 3b due to the chelating pyridyl unit. The HR-MS signal at $484.0715 \mathrm{amu}$ (theoretical value for $[\mathrm{M}-\mathrm{OTf}]^{+} 484.0730 \mathrm{amu}$ ) further supports the cationic nature of ruthenium complex 3b.

Similarly, the reaction of dimethylated salt $2 \mathbf{c}$ with the ruthenium precursor and a large excess of $\mathrm{NaOAc}$ yielded ruthenium complex $\mathbf{3 c}$ as a dark red solid which was purified by standard column 
chromatography on silica. These conditions therefore induce deprotonatation of the amide and also abstraction of one $\mathrm{CH}$ proton of the pyridinium ring. While deprotonation of amides with $\mathrm{NaOAc}$ is feasible ( $c f$ formation of $\mathbf{3 b}$ and formation of the free PYA ligand), ${ }^{5 a}$ the pKa of pyridinium salts is unfavourably high to plausibly rationalize a second deprotonation. ${ }^{11}$ Therefore, we surmise a stepwise cyclometalation process involving first PYA coordination to the metal center, followed by intramolecular $\mathrm{CH}$ activation by ruthenium and proton scavenging by the acetate ion in an amphiphilic metal-ligand activation (AMLA) process $^{8 \mathrm{a}, 12}$ to induce chelation (Scheme 2). A similar process is assumed for the formation of complex 3a, however ruthenium complex $\mathbf{3 c}$ produces a formally neutral mesoionic carbene ligand instead of the formally anionic phenyl ligand in complex 3a. The ${ }^{1} \mathrm{H}$ NMR spectrum of complex 3c shows both the disappearance of the NH unit and the loss of one aromatic proton, hence corroborating cyclometallation and pyridylidene formation. While the ${ }^{1} \mathrm{H}$ NMR spectrum of complex $\mathbf{3 b}$ shows the expected downfield shifts for the pyridyl protons upon coordination to the metal center, complex $\mathbf{3 c}$ only displays three signals due to the cyclometalated pyridylidene unit with only minor shifts $(\Delta \delta<0.1 \mathrm{ppm})$ compared to complex $\mathbf{3 b}$. The ${ }^{13} \mathrm{C}$ NMR spectrum of complex $\mathbf{3 c}$ shows the appearance of a new quaternary carbon corresponding to the cyclometallated carbene carbon bound to the ruthenium center $\left(\mathrm{C}_{\mathrm{carb}}-\mathrm{Ru}\right)$ at $171.0 \mathrm{ppm}$, which indicates a significant downfield shift of $\sim 40 \mathrm{ppm}$ from the corresponding $\mathrm{CH}_{\mathrm{pyr}}$ resonance of salt $\mathbf{2 c}$ upon coordination to ruthenium via cyclometallation. The $[\mathrm{M}-\mathrm{OTf}]^{+}$ion was observed by HR-MS at $498.0896 \mathrm{amu}$ (theoretical value $498.0881 \mathrm{amu}$ ), in agreement with the cationic nature of the ruthenium complex.

In addition, complexes 3d and 3e featuring a PYA moiety with a chelating second PYA unit and a triazolylidene, respectively (Figure 2), were synthesized according to published methods ${ }^{3 \mathrm{~b}, 5}$ for comparative purposes. The five complexes 3a-e all feature a PYA ligand as anchoring point and a chelating aromatic chelate comprised of either a C-donor (3a, $\mathbf{3} \mathbf{c}$ and $\mathbf{3 e}$ ) or a N-donor (3b and $\mathbf{3 d})$. In addition, these chelating groups can be divided into formally anionic (3a), neutral (3b), and zwitter- or mesoionic donor sites (3c-e), thus providing a useful set of complexes for comparison and quantification of the structural, electronic, and catalytic impact of these different donor groups.
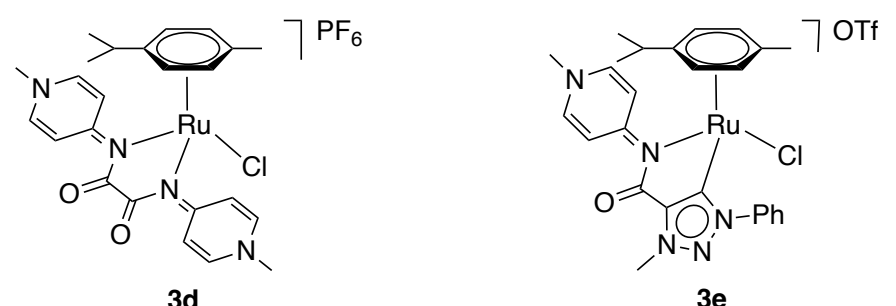

Figure 2. Complex 3d and 3e featuring a PYA moiety with a chelating second PYA unit and a triazolylidene, respectively.

Structural properties. All complexes were analyzed by single crystal X-ray diffraction. Their molecular structures all show the expected three-legged piano-stool geometry comprised of the cymene 
ligand as 'chair', and a chloride as well as the bidentate chelating PYA ligand as the 'legs' (Figure 3). Bond lengths and angles around the ruthenium center are almost identical within standard deviations for all five complexes (Table 1). For example, all the bond angles differ by less than $2^{\circ}$, which emphasizes the structural similarity of this series of complexes. The $\mathrm{Ru}-\mathrm{N}_{\mathrm{PYA}}$ bond is identical at 2.11(1) $\AA$ for all complexes except for 3e, which features a stretched bond with Ru-NPYA 2.161(1) A. This elongation may be a consequence of the five-membered triazolylidene heterocycle, which positions its 'ortho' substituents in a wider angle than the six-membered aromatic rings $\left(72^{\circ}\right.$ vs $\left.60^{\circ}\right)$. Moreover, the $\mathrm{Ru}-\mathrm{C}$ bonds to the chelating phenyl or carbene units is substantially shorter (2.03(2) $\AA$ ) than the $\mathrm{Ru}-\mathrm{N}$ bonds to the chelating $\mathrm{N}$-donor in $\mathbf{3 d}$ and $\mathbf{3 b}$ (2.108(3) and 2.079(2) $\AA$, respectively. This electronic difference of $\mathrm{C}$ - $v s \mathrm{~N}$-donor ligands is presumably also entailing the slight difference in the ruthenium-cymene interaction. The distance of the cymene centroid to the ruthenium center is slightly larger in the complexes with C-donors (1.705(2) $\AA$ ) when compared to the N-donor-functionalized PYA complexes (Ru-centroid 1.679(1) $\AA$ ). These subtle differences suggest that variation of the chelating group on the PYA ligand in the series of ruthenium complexes investigated here only marginally affects steric properties.

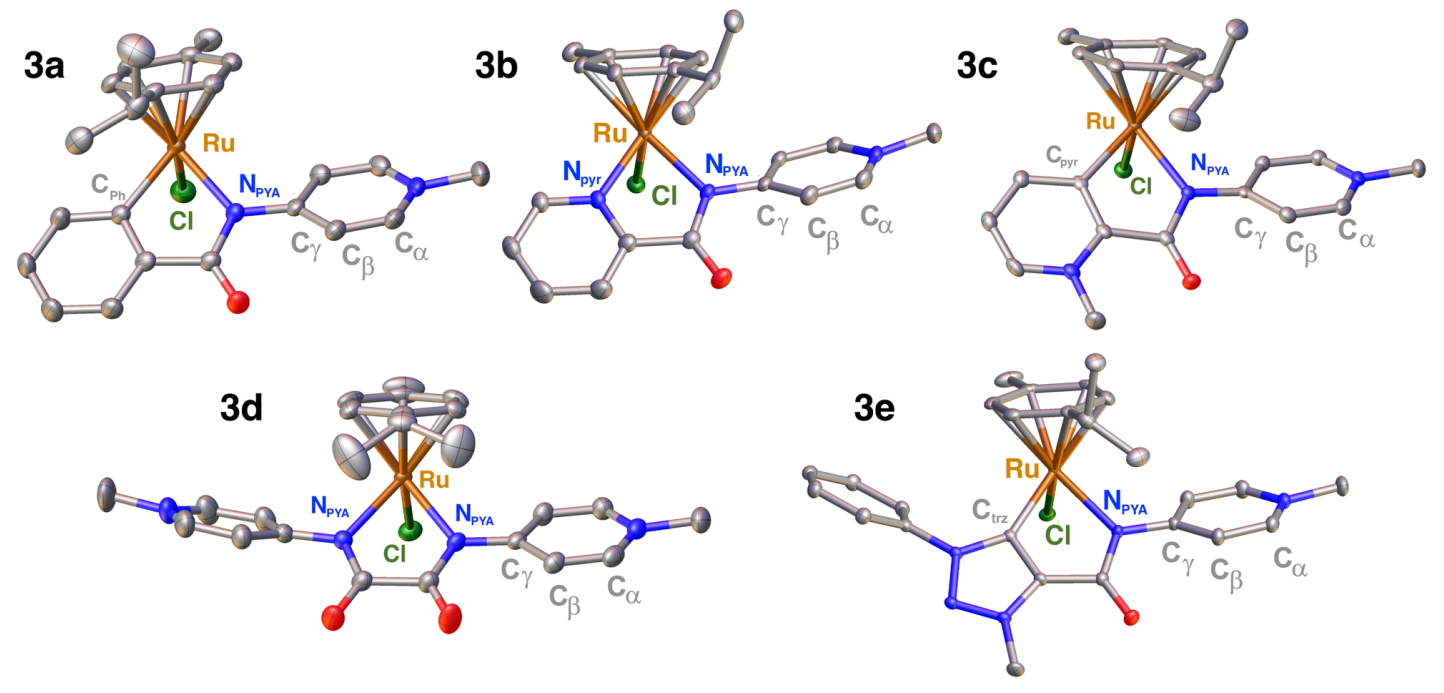

Figure 3. ORTEP representation of Ru-PYA complexes 3a-e (50\% probability; hydrogen atoms, counterions and co-crystallized solvent molecules omitted for clarity).

Examination of the PYA unit in all five complexes reveals some insights into the bonding of this ligand. The pyridyl $\mathrm{C}_{\alpha}-\mathrm{C}_{\beta}$ bonds (average 1.369(3) $\AA$ ) are consistently and significantly shorter compared to the $\mathrm{C}_{\beta}-\mathrm{C}_{\gamma}$ bonds (average 1.408(4) $\AA$; Table 2), which indicates substantial double bond localization. Such a bonding situation suggests considerable contribution of the neutral diene-type resonance structure $\mathbf{A}$ in the solid state ( $c f$ Fig. 1a), in agreement with previous solid state analyses. ${ }^{3,5}$ These bond lengths are almost identical in all five complexes, hence implying that the chelating group does not perturb the configuration of the pyridylidene heterocycle significantly. ${ }^{5 b}$ Further structural analyses focused on the geometry around the NPYA nucleus, which should show different features when bound as 
an imine or amide ( $c f$ resonance structures $\mathbf{A}$ and $\mathbf{B}$ in Fig. 1a). The three bond angles around $\mathrm{N}_{\text {PYA }}$ sum up to exactly $360^{\circ}$, confirming $\mathrm{sp}^{2}$ hybridization rather than a distortion towards a tetrahedral nitrogen geometry. Torsion angles between the carbonyl unit of the amide and the $\mathrm{N}-\mathrm{Ru}$ bond $\left(\mathrm{O}-\mathrm{C}-\mathrm{N}_{\mathrm{PYA}}-\mathrm{Ru}\right)$ are very closed to $180^{\circ}$, while the torsion angles between $\mathrm{NPYA}_{\mathrm{P}}-\mathrm{Ru}$ bond and the $\mathrm{C}_{\gamma}-\mathrm{C}_{\beta}$ bond of the PYA ligand are between $32^{\circ}$ and $42^{\circ}$. Almost identical absolute values were observed for the torsion angle formed by the $\mathrm{C}_{\gamma}-\mathrm{C}_{\beta}$ bond and the $\mathrm{N}_{\mathrm{PYA}}-\mathrm{C}_{\text {carbonyl }}$ bond. These data indicate that in the solid state, the $\mathrm{N}_{\text {PYA }}$ nucleus shows pronounced $\pi$ electron overlap with the carbonyl unit, yet essentially none with the pyridyl heterocycle. The heterocycle is twisted out of the nitrogen $\mathrm{sp}^{2}$ plane by about $40^{\circ}$ and therefore minimizes any $\pi$ orbital overlap. ${ }^{13}$ In agreement with this notion, the $\mathrm{NPYA}_{\mathrm{P}}-\mathrm{C}_{\gamma}$ bond length averages to 1.386(6) $\AA$ as expected for a $\mathrm{C}-\mathrm{N}$ single bond. These solid state analyses of the PYA unit therefore reveal considerable $\mathrm{C}=\mathrm{C}$ double bond localization of the heterocycle, yet $\mathrm{sp}^{2}$ hybridization of the $\mathrm{N}_{\mathrm{PYA}}$ nucleus with little imine contribution, i.e. a hybrid of the limiting resonance forms $\mathbf{A}$ and $\mathbf{B}$.

Table 1. Selected bond lengths $(\AA)$ and angles $\left(^{\circ}\right)$ around the Ru center of Ru-PYA complexes $\mathbf{3 a}-\mathbf{e}$.

\begin{tabular}{cccccc}
\hline & $\mathbf{3 a}$ & $\mathbf{3 b}$ & $\mathbf{3 c}$ & $\mathbf{3 d}^{a}$ & $\mathbf{3 e}^{b}$ \\
$\left(\mathrm{E}=\mathrm{C}_{\mathrm{Ph}}\right)$ & $\left(\mathrm{E}=\mathrm{N}_{\mathrm{pyr}}\right)$ & $\left(\mathrm{E}=\mathrm{C}_{\mathrm{pyr}}\right)$ & $\left(\mathrm{E}=\mathrm{N}_{\mathrm{PYA}}\right)$ & $\left(\mathrm{E}=\mathrm{C}_{\text {trz }}\right)$ \\
\hline $\mathrm{Ru}-\mathrm{N}_{\mathrm{PYA}}$ & $2.125(2)$ & $2.1043(15)$ & $2.114(2)$ & $2.097(2)$ & $2.1613(9)$ \\
$\mathrm{Ru}-\mathrm{E}$ & $2.044(3)$ & $2.0791(16)$ & $2.029(3)$ & $2.119(2)$ & $2.0119(11)$ \\
$\mathrm{Ru}-\mathrm{Cl}$ & $2.4281(8)$ & $2.40842(5)$ & $2.4150(7)$ & $2.4281(7)$ & $2.4091(3)$ \\
$\mathrm{Ru}-\mathrm{cym}$ centroid & $1.7070(12)$ & $1.6795(8)$ & $1.7031(16)$ & $1.6792(13)$ & $1.7029(5)$ \\
$\mathrm{E}-\mathrm{Ru}-\mathrm{N}_{\mathrm{PYA}}$ & $77.63(10)$ & $76.95(6)$ & $77.57(10)$ & $76.95(9)$ & $76.18(4)$ \\
$\mathrm{E}-\mathrm{Ru}-\mathrm{Cl}$ & $86.10(9)$ & $84.73(4)$ & $86.90(8)$ & $86.84(7)$ & $85.37(3)$ \\
$\mathrm{N}_{\text {PYA }}-\mathrm{Ru}-\mathrm{Cl}$ & $88.34(7)$ & $86.51(4)$ & $86.30(7)$ & $87.10(7)$ & $87.03(3)$ \\
\hline
\end{tabular}

${ }^{a}$.Data from reference $4 .{ }^{b}$ Data from reference $3 b$.

Table 2. Selected bond lengths $(\AA)$ and dihedral angles $\left(^{\circ}\right)$ pertaining to the PYA ligands environment of the Ru-PYA complexes $\mathbf{3 a}-\mathbf{e}$.

\begin{tabular}{cccccc}
\hline & $\mathbf{3 a}$ & $\mathbf{3 b}$ & $\mathbf{3 c}$ & $\mathbf{3 d}^{a}$ & $\mathbf{3 e}^{b}$ \\
\hline $\mathrm{av}(\mathrm{C} \alpha-\mathrm{C} \beta)$ & $1.366(6)$ & $1.369(4)$ & $1.371(6)$ & $1.371(9)$ & $1.3713(25)$ \\
$\mathrm{av}(\mathrm{C} \beta-\mathrm{C} \gamma)$ & $1.411(6)$ & $1.407(4)$ & $1.412(6)$ & $1.405(9)$ & $1.4052(24)$ \\
$\mathrm{N}_{\mathrm{PYA}}-\mathrm{C} \gamma$ & $1.382(3)$ & $1.389(2)$ & $1.385(4)$ & $1.390(6)$ & $1.3900(15)$ \\
$\mathrm{O}-\mathrm{C}-\mathrm{N}-\mathrm{Ru}$ & 177.23 & 178.50 & 177.90 & 170.79 & 176.19 \\
$\mathrm{Ru}-\mathrm{N}-\mathrm{C} \gamma-\mathrm{C} \beta$ & 31.91 & 41.06 & 34.49 & 41.80 & 41.99 \\
$\mathrm{C}-\mathrm{N}-\mathrm{C} \gamma-\mathrm{C} \beta$ & 28.72 & 38.71 & 34.32 & 31.06 & 38.71
\end{tabular}

${ }^{a}$.Data from reference 4; distances and angles are an average of the two PYA moieties. ${ }^{b}$ Data from reference $3 b$. 
Spectroscopic properties. The electronic impact of the different chelating groups was further studied by NMR spectroscopy. The ${ }^{1} \mathrm{H}$ NMR spectra of all five complexes were measured in $\mathrm{CD}_{2} \mathrm{Cl}_{2}$ as a nonpolar and non-coordinating solvent to evaluate the chemical shifts of the $\alpha$ and $\beta$ protons as diagnostic probes for the electronic structure of the PYA ligand. Accordingly the shift difference between the $\alpha$ and $\beta$ protons $\left(\Delta \delta=\delta_{\mathrm{H} \beta}-\delta_{\mathrm{H} \alpha}\right)$ provides a qualitative estimate of the relative contribution of the limiting resonance structures $\mathbf{A}$ and $\mathbf{B}$, with larger values indicating a larger contribution of the neutral diene structure $\mathbf{A}$ than when this value is small or even negative. ${ }^{3 a, 14}$ Despite the identical structure of the PYA unit in the solid state in all five complexes, the ${ }^{1} \mathrm{H}$ NMR data show considerable differences (Fig. 4). The shift difference $\Delta \delta$ in complex 3a is significantly larger than in the other complexes $(\Delta \delta=1.03$ ppm; Table 3). This difference gradually decreases with modification of the chelating site from phenyl $(1.03)>$ PYA $(0.74)>$ pyridylidene $(0.53)>\operatorname{trz}(0.41)>\operatorname{pyr}(0.27)$. This trend is correlating well with the expected donor properties of the chelating ligand (phenyl anion $>$ carbene $>$ pyridine), suggesting that the donor properties of the chelating site affects the electronic configuration of the pyridyl ring. This spectroscopic variation emphasizes the unique electronic flexibility of the PYA scaffold. Hence, strong donation of the chelating site enhances the electron density at the ruthenium center, which in turn increases $\pi$ backbonding to the PYA unit. Such backbonding favors the $\pi$ acidic imine-type resonance structure $\mathbf{A}$ as compared to resonance structure $\mathbf{B}$ with a $\pi$ basic amide ligation, resulting in a larger NMR chemical shift difference. According to this model, the mesoionic pyridylidene ligand is a stronger donor than the triazolylidene chelate, presumably because of the higher electrophilicity of the triazole heterocycle compared to the pyridine. These NMR data further suggest stronger donor properties of the PYA ligand when compared to N-heterocyclic carbenes. ${ }^{2 \mathrm{~d}}$ While the chemical shift difference provides a useful probe for estimating the donor properties of ancillary donor sites, ${ }^{5 \mathrm{a}}$ it should be noted that the PYA ligand is assumed to keep its predominant zwitterionic character in all complexes $\mathbf{3 a}-\mathbf{e}$.

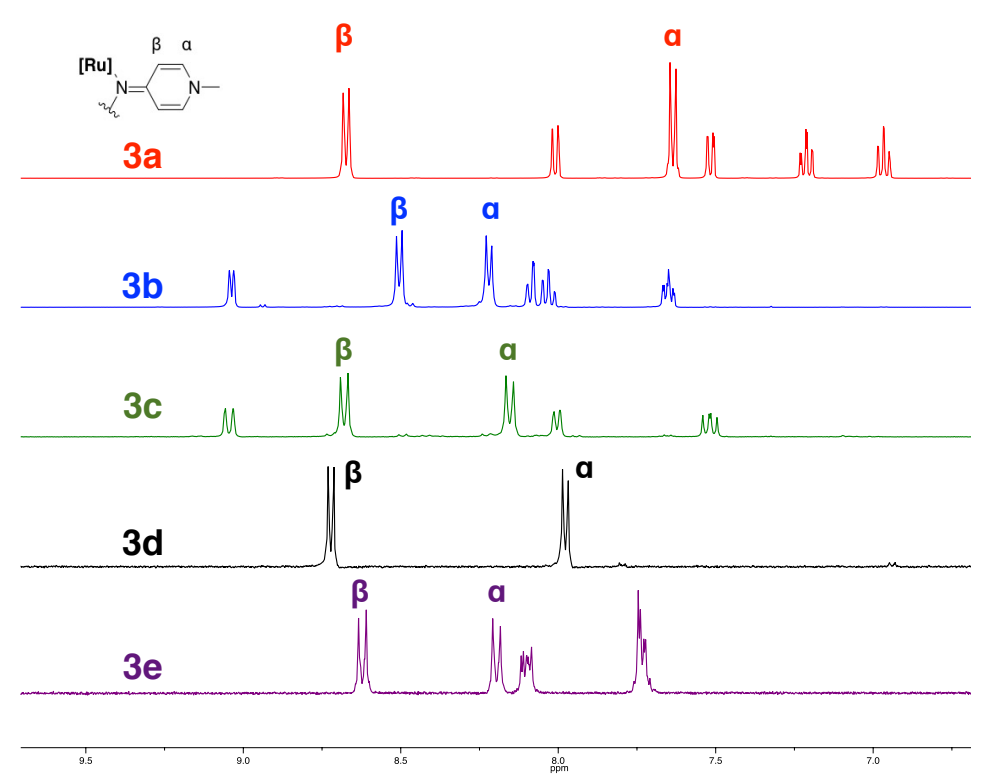


Figure 4. Aromatic region of the ${ }^{1} \mathrm{H}$ NMR spectrum of Ru-PYA complexes 3a-e indicating the diagnostic shift of the $\alpha$ and $\beta$ protons of the PYA ligand.

Table 3. ${ }^{1} \mathrm{H}$ and ${ }^{13} \mathrm{C}$ NMR shifts of the $\mathrm{CH} \alpha$ and $\mathrm{CH} \beta$ units for Ru-PYA complexes 3a-e. ${ }^{a}$

\begin{tabular}{cccccc}
\hline Complex & $\mathrm{H} \alpha$ & $\mathrm{H} \beta$ & $\Delta \delta(\mathrm{H})$ & $\mathrm{C} \alpha$ & $\mathrm{C} \beta$ \\
\hline 3a & 7.64 & 8.67 & 1.03 & 141.1 & 122.0 \\
3b & 8.23 & 8.50 & 0.27 & 144.0 & 124.5 \\
3c & 8.15 & 8.68 & 0.53 & 143.1 & 124.2 \\
3d & 7.98 & 8.72 & 0.74 & 143.7 & 122.4 \\
3e & 8.17 & 8.58 & 0.41 & 139.9 & 123.5 \\
\hline
\end{tabular}

${ }^{a}$ data for complexes $\mathbf{3 d}$ and $\mathbf{3 e}$ from reference 4 and $3 b$.

Electrochemical properties. Electrochemical analysis of related ruthenium complexes containing a PYA ligand showed that the $\mathrm{Ru}^{\mathrm{II} / \mathrm{II}}$ oxidation potential depends considerably on the solvent. ${ }^{3}$ This difference was attributed to the ability of the PYA ligand to adapt to the polarity of the medium, with lower oxidation potentials in polar solvents, which impart larger contribution of zwitterionic resonance structure contribution and X-type PYA bonding to the ruthenium center, while apolar solvents favoured contribution from the neutral diene form and hence weaker donation, resulting in higher oxidation potentials. Here we have used electrochemical analyses to evaluate the influence of the chelate site rather than the solvent, and therefore, measurements were performed in only one solvent to allow for a direct comparison. Cyclic voltammetry $(\mathrm{CV})$ in $\mathrm{CH}_{2} \mathrm{Cl}_{2}$ in the -1.5 to $+1.7 \mathrm{~V}$ range revealed a fully reversible and presumably ruthenium-centered oxidation and a reduction below $-1 \mathrm{~V}$ that is reversible for all complexes but $\mathbf{3 e}$ and is likely associated with heterocyle reduction (Fig. S11-15). The oxidation is easiest for complex 3a and occurs at $E_{1 / 2}=+0.59 \mathrm{~V} v s$ SCE (Figure 5, Table 4). At the other end of the scale, an oxidation potential of $+1.38 \mathrm{~V}$ was observed for $\mathbf{3 b}$, indicating a substantial difference in electron density at the metal depending on the chelating group. This large potential difference also identifies electrochemistry as a sensitive probe for quantifying the impact of the chelate donor. As expected, the zwitter- and mesoionic ligands induce ruthenium oxidation potentials in between the two extremes of a strictly neutral and anionic ligands. Complexes $\mathbf{3 d}$ and $\mathbf{3 e}$ feature essentially identical redox potentials $\left(E_{1 / 2}=+1.21\right.$ and $+1.20 \mathrm{~V}$, respectively), while the oxidation of the pyridylidene complex $3 \mathbf{c}$ occurs at lower potential $\left(E_{1 / 2}=+0.98\right)$. These data suggest about equal donor properties of the PYA and triazolylidene ligand, and stronger donation of the pyridylidene ligand. This sequence is in general agreement with the NMR spectroscopic data (phenyl $>$ pyridylidene $>$ triazolylidene $>$ pyridine) though the donor properties of the PYA ligand are weaker according to these electrochemical measurements when compared to NMR analysis. This discrepancy may arise from the fact that NMR spectroscopy evaluates the ligand electronic configuration, while electrochemistry focuses on the density at the metal center. 


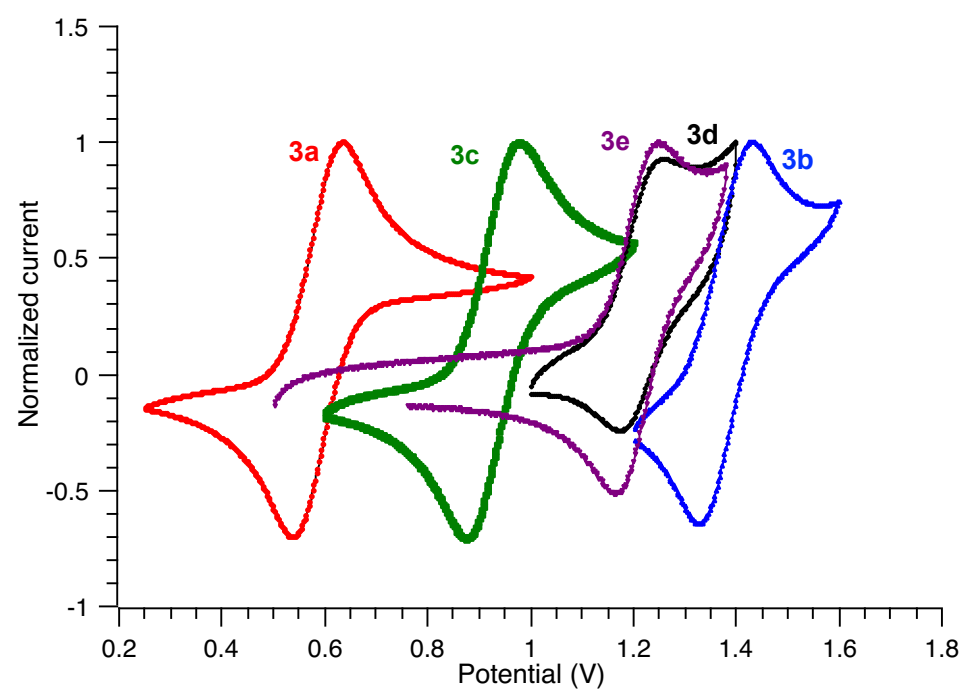

Figure 5. Superimposed normalized CV plots of Ru-PYA complexes 3a (red), 3b (blue), 3c (green), 3d (black) and $3 \mathbf{e}$ (purple) in $\mathrm{CH}_{2} \mathrm{Cl}_{2}$.

Table 4. Electrochemical data for Ru-PYA complexes $\mathbf{3 a}-\mathbf{e}{ }^{a}$

\begin{tabular}{ccc}
\hline Complex & $\mathrm{E}_{1 / 2}(\mathrm{~V})$ & $\Delta \mathrm{E}(\mathrm{mV})$ \\
\hline $\mathbf{3 a}$ & +0.59 & 98 \\
$\mathbf{3 b}$ & +1.38 & 103 \\
$\mathbf{3 c}$ & +0.98 & 103 \\
$\mathbf{3 d}$ & +1.21 & 83 \\
$\mathbf{3 e}^{b}$ & +1.20 & 85
\end{tabular}

${ }^{a}$ Sweep rate $400 \mathrm{mV} \mathrm{s}^{-1}$, potentials vs SCE referenced to $\mathrm{Fc}^{+} / \mathrm{Fc} .{ }^{b}$ Data for complex $3 \mathbf{e}$ from reference $3 b$.

Catalytic transfer hydrogenation. The impact of different chelating groups in the PYA ligand was probed in ruthenium-catalyzed transfer hydrogenation of ketones. ${ }^{15}$ Benzophenone was used as a model substrate to compare the activity of all five Ru-PYA complexes. Under standard transfer hydrogenation conditions ${ }^{16}$ using $i \mathrm{PrOH}$ as both the dihydrogen source and solvent and $\mathrm{KOH}$ as base $(100: 10: 1$ substrate/base/catalyst ratio) significantly diverse catalytic activity was observed for the different RuPYA complexes (Figure 6, Table S1). Complex 3a displayed good activity and reached essentially full conversion within $4 \mathrm{~h}$ at $1 \mathrm{~mol} \%$ loading. This activity is the highest in the series evaluated here. Ruthenium complexes bearing a chelating carbene donor ligand ( $\mathbf{3 c}$ and $\mathbf{3 e}$ ) or the zwitterionic PYA as chelating group (3d) gave significantly slower catalysts. They exhibited almost identical catalytic activity and reached full conversion only within about $24 \mathrm{~h}$. The lowest activity was measured for the complex containing the weakest donor ligand (3b), which accomplished a modest $45 \%$ conversion after $24 \mathrm{~h}$. While the activity of these complexes is much lower than those of high-performing ruthenium 
complexes,${ }^{17}$ it is worth noting that the catalytic activity strongly correlates with the trends deduced from NMR-spectroscopic and electrochemical analyses. This correlation suggests that both sites of the chelating ligand remain bound to the ruthenium center and that the modification of the second coordination site is critical for designing active ligands. The correlation further indicates that the catalytic activity can be rationally tailored by enhancing the ligand donor properties in these $\left[\operatorname{RuCl}(\mathrm{cym})\left(\mathrm{L}^{\wedge} \mathrm{PYA}\right)\right]^{+}$scaffolds.

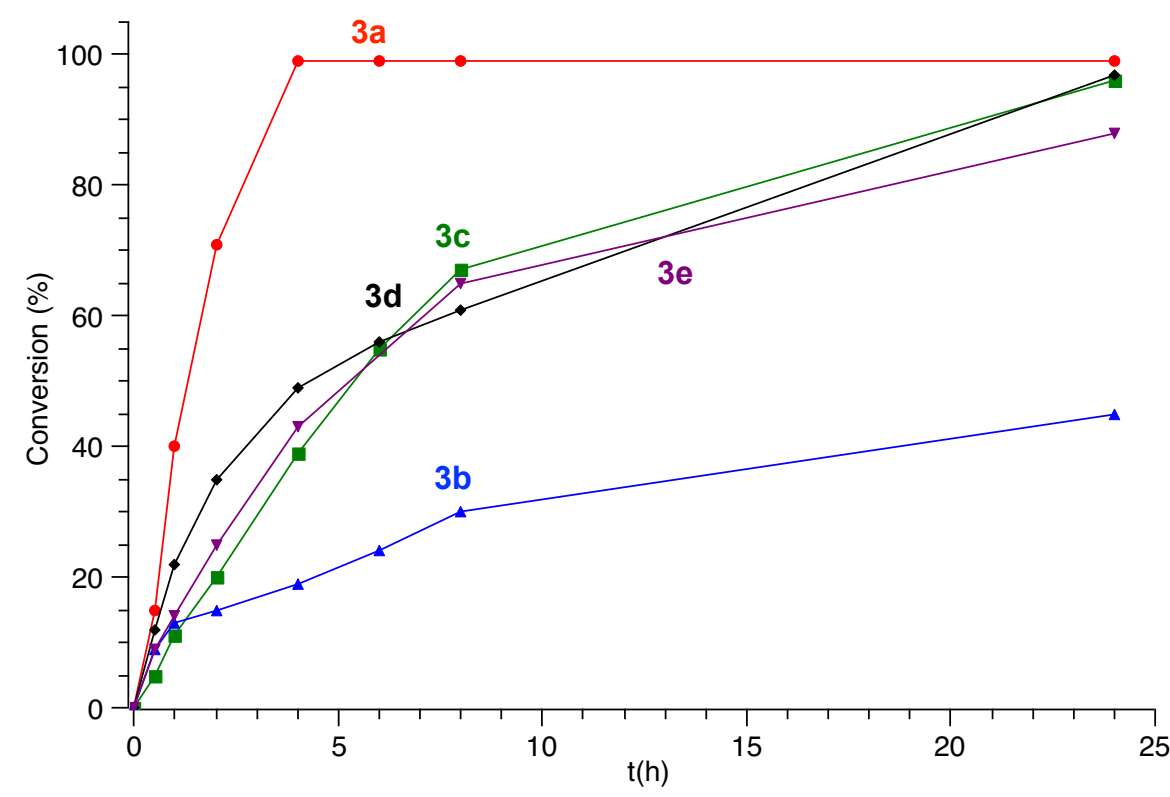

Figure 6. Time-conversion profiles for the transfer hydrogenation of benzophenone with Ru-PYA complexes 3a (red), 3b (blue), 3c (green), 3d (black), and $\mathbf{3 e}$ (purple).

Analysis of initial rates for benzophenone conversion were performed by assuming a first order rate law. A logarithmic plot of the change in substrate concentration $v$ s time indeed produced a linear fit for the conversions accomplished with all complexes 3a-e (Figure 7), strongly suggesting that these ruthenium complexes operate through a mononuclear reaction mechanism. Notably, benzophenone consumption using complexes $\mathbf{3 d}$ fits slightly better when assuming a second-order rate law, as indicated by the linear fit of a plot of the reciprocal substrate consumption $v$ s time (Fig. S1, S2). However, runs at different catalyst concentrations in the $0.5-2 \mathrm{~mol} \%$ range indicate that also reactions with complex $\mathbf{3 d}$ follow first-order kinetics. When considering the initial rates, complex 3a shows the highest activity that is about 4 times larger than that of the carbene-PYA complexes $\mathbf{3} \mathbf{c}-\mathbf{e}$. Complex, $\mathbf{3 b}$ is the slowest and more than 20 times less active than $\mathbf{3 a}$. 


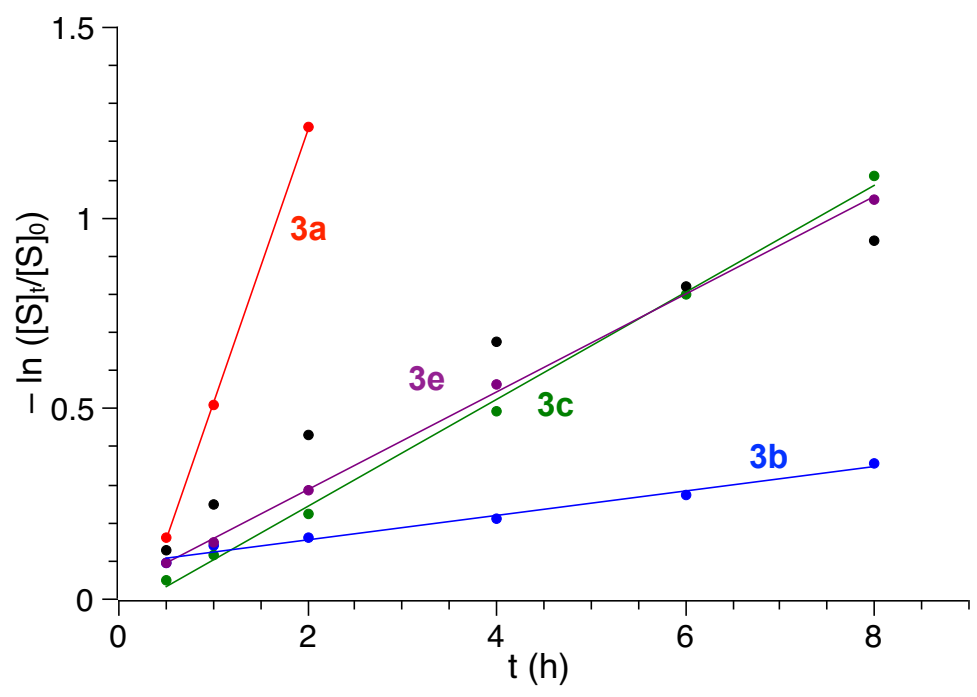

Figure 7. Conversion rates for the transfer hydrogenation of benzophenone with Ru-PYA complexes fitted against a first order reaction rate (solid line) for $\mathbf{3 a}$ (red; $\left.\mathrm{k}=0.718, \mathrm{R}^{2}=0.999\right)$, $\mathbf{3 b}$ (blue; $\mathrm{k}=$ $\left.0.032, \mathrm{R}^{2}=0.985\right), 3 \mathbf{c}\left(\right.$ green; $\left.\mathrm{k}=0.141, \mathrm{R}^{2}=0.997\right)$, and $\mathbf{3 e}$ (purple; $\left.\mathrm{k}=0.128, \mathrm{R}^{2}=0.999\right)$, see $\mathrm{SI}$ for evaluation of $\mathbf{3 d}$.

\section{Conclusions}

The donor properties of pyridylideneamide (PYA) as a ligand has been qualitatively assessed by comparison of a series of structurally highly similar complexes [RuCl(cym)(PYA-L)] with variable chelating sites L. Electrochemical and spectroscopic comparison indicates a marked trend of donor ability that decreases in the series $\mathrm{L}=$ phenyl $>\mathrm{PYA} \approx \mathrm{N}$-heterocyclic carbene $>$ pyridine, demonstrating that PYA ligands are remarkably strong donors in these ruthenium complexes. Moreover, this series indicates a high tunability of the electronic properties of the metal center, as demonstrated in catalytic transfer hydrogenation. Such tailoring underlines the relevance of ligand design for improving electronic and catalytic properties and establishes PYA ligands as an attractive ligand platform with vast synthetic opportunities for catalysis.

\section{Experimental part}

General. Compounds 1a, 2a, 2b, 3d and 3e were all synthetized as reported in the literature. ${ }^{3 \mathrm{~b}, 410 \mathrm{a}}$ All other reagents were commercially available and used as received. Unless specified otherwise, NMR spectra were recorded at $25{ }^{\circ} \mathrm{C}$ on Bruker spectrometers operating at 300 or $400 \mathrm{MHz}$ ( ${ }^{1} \mathrm{H} \mathrm{NMR}$ ), and $100 \mathrm{MHz}\left({ }^{13} \mathrm{C} \mathrm{NMR}\right)$, respectively. Chemical shifts ( $\delta$ in ppm, coupling constants $J$ in $\mathrm{Hz}$ ) were referenced to residual solvent signals $\left({ }^{1} \mathrm{H},{ }^{13} \mathrm{C}\right)$. Assignments are based on homo- and heteronuclear shift correlation spectroscopy. Purity of bulk samples of the complexes has been established by NMR spectroscopy, and when possible by elemental analysis. Elemental analyses were performed at DCB Microanalytic Laboratory using a Thermo Scientific Flash 2000 CHNS-O elemental analyzer, residual 
solvent was confirmed by NMR spectroscopy and also by X-ray structure determinations. Highresolution mass spectrometry was carried out with a Thermo Scientific LTQ Orbitrap XL (ESI-TOF).

Compound 1b. A slightly modified literature procedure was employed. ${ }^{10 a}$ Picolinic acid (1.23 g, 10 mmol) was refluxed in $\mathrm{SOCl}_{2}(10 \mathrm{~mL}, 140 \mathrm{mmol})$ under $\mathrm{N}_{2}$ for $3 \mathrm{~h}$. Excess of $\mathrm{SOCl}_{2}$ was removed under reduced pressure. Without further purification, the residue was dissolved in THF $(20 \mathrm{~mL})$ and added dropwise to a solution of 4-aminopyridine $(941 \mathrm{mg}, 10 \mathrm{mmol})$ and $\mathrm{NEt}_{3}(2.8 \mathrm{~mL}, 20 \mathrm{mmol})$ in THF (80 $\mathrm{mL}$ ). The reaction mixture was stirred at r.t. for $18 \mathrm{~h}$ upon which a dark grey precipitate formed. The precipitate was removed by filtration and washed with THF $(50 \mathrm{~mL})$. The filtrates were combined and, all volatiles were removed in vacuo to give a white solid. This solid was purified by column chromatography $\left(\mathrm{SiO}_{2}\right.$; pentane/EtOAc 3:7) to yield compound $\mathbf{1 b}$ as pale brown solid $(1.69 \mathrm{~g}, 85 \%)$. Analytical data are identical to those reported.

Compound 2c. Compound $\mathbf{1 b}(200 \mathrm{mg}, 1.0 \mathrm{mmol})$ was dissolved in 1,2-dichloroethane $(10 \mathrm{~mL})$ in a pressure tube. MeOTf $(1.2 \mathrm{~mL}, 10 \mathrm{mmol})$ was added and the reaction was stirred for $18 \mathrm{~h}$ at $100{ }^{\circ} \mathrm{C}$. The solution was cooled to r.t. and the formed white precipitate was filtered off and washed with $\mathrm{CH}_{2} \mathrm{Cl}_{2}$ $(100 \mathrm{~mL})$. The crude solid was dissolved in $\mathrm{MeCN}(5 \mathrm{~mL})$ and $\mathrm{Et}_{2} \mathrm{O}(40 \mathrm{~mL})$ was added to precipitate the title product, which was collected by filtration and dried thoroughly to afford compound $\mathbf{2 c}$ as a white solid (280 mg, 53\%).

${ }^{1} \mathrm{H}$ NMR (400 MHz, $d_{6}$-DMSO): $\delta 12.50(\mathrm{~s}, 1 \mathrm{H}, \mathrm{NH}), 9.22\left(\mathrm{dd},{ }^{3} J_{\mathrm{HH}}=6.1,{ }^{4} J_{\mathrm{HH}}=1.3 \mathrm{~Hz}, 1 \mathrm{H}, \mathrm{CH}_{\mathrm{pyr}}\right)$, $8.87\left(\mathrm{~m}, 1 \mathrm{H}, \mathrm{CH}_{\mathrm{pyr}}\right), 8.86\left(\mathrm{~d},{ }^{3} J_{\mathrm{HH}}=7.3 \mathrm{~Hz}, 2 \mathrm{H}, \mathrm{CH}_{\mathrm{pyr}}\right), 8.54\left(\mathrm{dd},{ }^{3} J_{\mathrm{HH}}=7.9,{ }^{4} J_{\mathrm{HH}}=1.5 \mathrm{~Hz}, 1 \mathrm{H}, \mathrm{CH}_{\mathrm{pyr}}\right)$, $8.36\left(\mathrm{ddd},{ }^{3} J_{\mathrm{HH}}=7.9,6.1,{ }^{4} J_{\mathrm{HH}}=1.5 \mathrm{~Hz}, 1 \mathrm{H}, \mathrm{CH}_{\mathrm{pyr}}\right), 8.20\left(\mathrm{~d},{ }^{3} \mathrm{~J}_{\mathrm{HH}}=7.3 \mathrm{~Hz}, 2 \mathrm{H}, \mathrm{CH}_{\mathrm{pyr}}\right), 4.45(\mathrm{~s}, 3 \mathrm{H}$, $\left.\mathrm{NCH}_{3}\right), 4.27$ (s, 3H, NCH 3$) .{ }^{13} \mathrm{C}\left\{{ }^{1} \mathrm{H}\right\} \mathrm{NMR}\left(100 \mathrm{MHz}, d_{6}\right.$-DMSO): $\delta 160.0(\mathrm{CO}), 150.4\left(\mathrm{C}_{\mathrm{pyr}}\right), 148.6$ $\left(\mathrm{CH}_{\mathrm{pyr}}\right), 146.6\left(\mathrm{CH}_{\mathrm{pyr}}\right), 146.5\left(\mathrm{CH}_{\mathrm{pyr}}\right), 145.2\left(\mathrm{C}_{\mathrm{pyr}}\right), 129.7\left(\mathrm{CH}_{\mathrm{pyr}}\right), 128.1\left(\mathrm{CH}_{\mathrm{pyr}}\right), 120.7\left(\mathrm{q},{ }^{1} J_{\mathrm{CF}}=322.3\right.$ $\left.\mathrm{Hz}, \mathrm{CF}_{3}\right), 116.4\left(\mathrm{CH}_{\mathrm{pyr}}\right), 47.1\left(\mathrm{NCH}_{3}\right), 46.9\left(\mathrm{NCH}_{3}\right)$. Elem. Anal. Calcd. for $\mathrm{C}_{15} \mathrm{H}_{15} \mathrm{~F}_{6} \mathrm{~N}_{3} \mathrm{O}_{7} \mathrm{~S}_{2}: \mathrm{C}, 34.16$; H, 2.87; N, 7.97. Found: C, 33.89; H, 2.10; N, 7.90. HR-MS: m/z calculated for $\mathrm{C}_{13} \mathrm{H}_{15} \mathrm{~N}_{3} \mathrm{O}_{2}[\mathrm{M}-2 \mathrm{OTf}]^{2+}$ $=114.5602$; found, 114.5599 .

Complex 3a. Compound 2a (136 mg, $0.40 \mathrm{mmol})$ was suspended in $\mathrm{CH}_{2} \mathrm{Cl}_{2}(5 \mathrm{~mL})$ into a separating funnel. Aqueos $\mathrm{NaOH}(10 \mathrm{~mL}, 2 \mathrm{M})$ was added. After vigorous mixing, the organic phase was collected. The aqueous layer was extracted with twice with $\mathrm{CH}_{2} \mathrm{Cl}_{2}(10 \mathrm{~mL})$. The organic layers were dried over anyhdrous $\mathrm{Na}_{2} \mathrm{SO}_{4}$ and filtered. All volatiles were removed, thus giving a the PYA free ligand as a white solid, which was used without further purification. The PYA free ligand, NaOAc (33 mg, $0.40 \mathrm{mmol}$ ) $\left[\mathrm{RuCl}_{2}(\mathrm{cym})\right]_{2}(123 \mathrm{mg}, 0.20 \mathrm{mmol})$ were dissolved in $\mathrm{CH}_{2} \mathrm{Cl}_{2}(25 \mathrm{~mL})$ and stirred at $\mathrm{rt}$ for $3 \mathrm{~h}$. All volatiles were removed under reduced pressure and the crude solid was purified by column chromatography ( $\mathrm{SiO}_{2} ; \mathrm{CH}_{2} \mathrm{Cl}_{2} /$ Acetone 1:1), thus yielding compound 3a as a red solid (121 mg, 61\%). 
Crystals suitable for X-ray diffraction were grown by slow diffusion of pentane into a solution of complex 3a in $\mathrm{CH}_{2} \mathrm{Cl}_{2}$.

${ }^{1} \mathrm{H}$ NMR (300 MHz, $\left.\mathrm{CD}_{2} \mathrm{Cl}_{2}\right): \delta 8.67\left(\mathrm{~d},{ }^{3} J_{\mathrm{HH}}=7.4 \mathrm{~Hz}, 2 \mathrm{H}, \mathrm{CH}_{\mathrm{PYA}}\right), 8.01\left(\mathrm{dd},{ }^{3} J_{\mathrm{HH}}=7.5,{ }^{4} J_{\mathrm{HH}}=1.1 \mathrm{~Hz}\right.$, $\left.1 \mathrm{H}, \mathrm{CH}_{\mathrm{Ph}}\right), 7.64\left(\mathrm{~d},{ }^{3} J_{\mathrm{HH}}=7.4 \mathrm{~Hz}, 2 \mathrm{H}, \mathrm{CH}_{\mathrm{PYA}}\right), 7.52\left(\mathrm{dd},{ }^{3} J_{\mathrm{HH}}=7.5,{ }^{4} J_{\mathrm{HH}}=1.5 \mathrm{~Hz}, 1 \mathrm{H}, \mathrm{CH}_{\mathrm{Ph}}\right), 7.21(\mathrm{td}$, $\left.{ }^{3} J_{\mathrm{HH}}=7.5,{ }^{4} J_{\mathrm{HH}}=1.5 \mathrm{~Hz}, 1 \mathrm{H}, \mathrm{CH}_{\mathrm{Ph}}\right), 6.97\left(\mathrm{td},{ }^{3} J_{\mathrm{HH}}=7.5,{ }^{4} J_{\mathrm{HH}}=1.1 \mathrm{~Hz}, 1 \mathrm{H}, \mathrm{CH}_{\mathrm{Ph}}\right), 5.27\left(\mathrm{dd},{ }^{3} J_{\mathrm{HH}}=5.8\right.$, $\left.{ }^{4} J_{\mathrm{HH}}=1.1 \mathrm{~Hz}, 1 \mathrm{H}, \mathrm{CH}_{\mathrm{cym}}\right), 5.19\left(\mathrm{dd},{ }^{3} J_{\mathrm{HH}}=5.8,{ }^{4} J_{\mathrm{HH}}=1.1 \mathrm{~Hz}, 1 \mathrm{H}, \mathrm{CH}_{\mathrm{cym}}\right), 5.00\left(\mathrm{dd},{ }^{3} J_{\mathrm{HH}}=5.8,{ }^{4} J_{\mathrm{HH}}=\right.$ $\left.1.1 \mathrm{~Hz}, 1 \mathrm{H}, \mathrm{CH}_{\mathrm{cym}}\right), 4.94\left(\mathrm{dd},{ }^{3} \mathrm{~J}_{\mathrm{HH}}=5.8,{ }^{4} J_{\mathrm{HH}}=1.1 \mathrm{~Hz}, 1 \mathrm{H}, \mathrm{CH}_{\mathrm{cym}}\right), 3.63\left(\mathrm{~s}, 3 \mathrm{H}, \mathrm{NCH}_{3}\right), 2.22$ (septet, $\left.{ }^{3} J_{\mathrm{HH}}=6.9 \mathrm{~Hz}, 1 \mathrm{H}, \mathrm{CHMe}_{2}\right), 1.97\left(\mathrm{~s}, 3 \mathrm{H}, \mathrm{cym}-\mathrm{CH}_{3}\right), 0.94\left(\mathrm{~d},{ }^{3} J_{\mathrm{HH}}=6.9 \mathrm{~Hz}, 3 \mathrm{H}, \mathrm{CH}-\mathrm{CH}_{3}\right), 0.93\left(\mathrm{~d},{ }^{3} J_{\mathrm{HH}}\right.$ $\left.=6.9 \mathrm{~Hz}, 3 \mathrm{H}, \mathrm{CH}-\mathrm{CH}_{3}\right) .{ }^{13} \mathrm{C}\left\{{ }^{1} \mathrm{H}\right\} \mathrm{NMR}\left(100 \mathrm{MHz}, \mathrm{CD}_{2} \mathrm{Cl}_{2}\right): \delta 180.8(\mathrm{CO}), 179.3\left(\mathrm{C}_{\mathrm{Ph}}-\mathrm{Ru}\right), 167.2$ $\left(\mathrm{C}_{\mathrm{PYA}}\right), 142.0\left(\mathrm{C}_{\mathrm{Ph}}\right), 141.1$ (CHPY $), 139.9\left(\mathrm{CH}_{\mathrm{Ph}}\right), 131.0\left(\mathrm{CH}_{\mathrm{Ph}}\right), 128,0\left(\mathrm{CH}_{\mathrm{Ph}}\right), 122.6\left(\mathrm{CH}_{\mathrm{Ph}}\right), 122.0$ (CHPYA), $98.5\left(\mathrm{C}_{\text {cym }}\right), 98.4\left(\mathrm{C}_{\text {cym }}\right), 92.2\left(\mathrm{CH}_{\text {cym }}\right), 88.5\left(\mathrm{CH}_{\text {cym }}\right), 84.9\left(\mathrm{CH}_{\text {cym }}\right), 83.5\left(\mathrm{CH}_{\text {cym }}\right), 45.6\left(\mathrm{NCH}_{3}\right)$, $31.2\left(\mathrm{CHMe}_{2}\right), 22.8\left(\mathrm{cym}-\mathrm{CH}_{3}\right), 22.1\left(\mathrm{CH}-\mathrm{CH}_{3}\right), 18.8\left(\mathrm{CH}-\mathrm{CH}_{3}\right)$. Elem. Anal. Calcd. for $\mathrm{C}_{23} \mathrm{H}_{25} \mathrm{ClN}_{2} \mathrm{ORu} \times 0.2 \mathrm{H}_{2} \mathrm{O}: \mathrm{C}, 56.89 ; \mathrm{H}, 5.27 ; \mathrm{N}, 5.77$; Found: C, 57.23; H, 5.17; N, 5.34. HR-MS: m/z calculated for $\mathrm{C}_{23} \mathrm{H}_{25} \mathrm{~N}_{2} \mathrm{ORu}[\mathrm{M}-\mathrm{Cl}]^{+}=447.1010$; found, 447.1011.

Complex 3b. Compound $2 \mathbf{b}$ ( $80 \mathrm{mg}, 0.22 \mathrm{mmol}), \mathrm{NaOAc}(90 \mathrm{mg}, 1.1 \mathrm{mmol})$ and $\left[\mathrm{RuCl}_{2}(\mathrm{cym})\right]_{2}(61$ $\mathrm{mg}, 0.1 \mathrm{mmol})$ were dissolved in $\mathrm{CH}_{2} \mathrm{Cl}_{2}(50 \mathrm{~mL})$ and the reaction mixture was stirred for $18 \mathrm{~h}$ at $\mathrm{rt}$. All volatiles were removed under reduced pressure and the crude solid was purified by column chromatography $\left(\mathrm{SiO}_{2} ; \mathrm{CH}_{2} \mathrm{Cl}_{2} /\right.$ Acetone 1:1) yielding compound $\mathbf{3 b}$ as an orange solid (58 $\left.\mathrm{mg}, 42 \%\right)$. Analytically pure microcrystalline material was obtained by precipitation a $\mathrm{MeOH}$ solution of the complex with $\mathrm{Et}_{2} \mathrm{O}$. Crystals suitable for $\mathrm{X}$-ray diffraction analysis were grown by slow evaporation of an $\mathrm{Et}_{2} \mathrm{O} / \mathrm{CH}_{2} \mathrm{Cl}_{2}$ solution of complex $\mathbf{3 b}$.

${ }^{1} \mathrm{H}$ NMR (400 MHz, $\left.\mathrm{CD}_{2} \mathrm{Cl}_{2}\right): \delta 9.04\left(\mathrm{~d},{ }^{3} J_{\mathrm{HH}}=5.5 \mathrm{~Hz}, 1 \mathrm{H}, \mathrm{CH}_{\mathrm{pyr}}\right), 8.50\left(\mathrm{~d},{ }^{3} J_{\mathrm{HH}}=6.8 \mathrm{~Hz}, 2 \mathrm{H}, \mathrm{CH}_{\mathrm{PYA}}\right)$, $8.22\left(\mathrm{~d},{ }^{3} J_{\mathrm{HH}}=6.8 \mathrm{~Hz}, 2 \mathrm{H}, \mathrm{CH}_{\mathrm{PYA}}\right), 8.09\left(\mathrm{dd},{ }^{3} J_{\mathrm{HH}}=7.5,{ }^{4} J_{\mathrm{HH}}=1.6 \mathrm{~Hz}, 1 \mathrm{H}, \mathrm{CH}_{\mathrm{pyr}}\right), 8.03\left(\mathrm{td},{ }^{3} J_{\mathrm{HH}}=7.5\right.$, $\left.{ }^{4} J_{\mathrm{HH}}=1.4 \mathrm{~Hz}, 1 \mathrm{H}, \mathrm{CH}_{\mathrm{pyr}}\right), 7.65\left(\mathrm{ddd},{ }^{3} J_{\mathrm{HH}}=7.5,5.5,{ }^{4} J_{\mathrm{HH}}=1.6 \mathrm{~Hz}, 1 \mathrm{H}, \mathrm{CH}_{\mathrm{pyr}}\right), 5.50\left(\mathrm{~d},{ }^{3} J_{\mathrm{HH}}=5.9 \mathrm{~Hz}\right.$, $\left.1 \mathrm{H}, \mathrm{CH}_{\mathrm{cym}}\right), 5.46\left(\mathrm{~d},{ }^{3} J_{\mathrm{HH}}=5.9 \mathrm{~Hz}, 1 \mathrm{H}, \mathrm{CH}_{\mathrm{cym}}\right), 5.43\left(\mathrm{~d},{ }^{3} J_{\mathrm{HH}}=5.9 \mathrm{~Hz}, 1 \mathrm{H}, \mathrm{CH}_{\mathrm{cym}}\right), 5.32\left(\mathrm{~d},{ }^{3} J_{\mathrm{HH}}=5.9\right.$ $\left.\mathrm{Hz}, 1 \mathrm{H}, \mathrm{CH}_{\mathrm{cym}}\right), 4.21\left(\mathrm{~s}, 3 \mathrm{H}, \mathrm{NCH}_{3}\right), 2.55$ (septett, $\left.{ }^{3} \mathrm{~J}_{\mathrm{HH}}=6.9 \mathrm{~Hz}, 1 \mathrm{H}, \mathrm{CHMe}_{2}\right), 2.28\left(\mathrm{~s}, 3 \mathrm{H}, \mathrm{cym}-\mathrm{CH}_{3}\right)$, $1.22\left(\mathrm{~d},{ }^{3} \mathrm{~J}_{\mathrm{HH}}=6.9 \mathrm{~Hz}, 3 \mathrm{H}, \mathrm{CH}-\mathrm{CH}\right), 1.05\left(\mathrm{~d},{ }^{3} \mathrm{~J}_{\mathrm{HH}}=6.9 \mathrm{~Hz}, 3 \mathrm{H}, \mathrm{CH}-\mathrm{CH}\right) .{ }^{13} \mathrm{C} \mathrm{NMR}(100 \mathrm{MHz}$, $\left.\mathrm{CD}_{2} \mathrm{Cl}_{2}\right): \delta 169.2(\mathrm{CO}), 167.0\left(\mathrm{C}_{\mathrm{PYA}}\right), 154.7\left(\mathrm{CH}_{\mathrm{pyr}}\right), 153.8\left(\mathrm{C}_{\mathrm{pyr}}\right), 144.0\left(\mathrm{CH}_{\mathrm{PYA}}\right), 139.9\left(\mathrm{CH}_{\mathrm{pyr}}\right), 129.1$ $\left(\mathrm{CH}_{\mathrm{pyr}}\right), 127.2\left(\mathrm{CH}_{\mathrm{pyr}}\right), 124.5\left(\mathrm{CH}_{\mathrm{PYA}}\right), 104.2\left(\mathrm{C}_{\text {cym }}\right), 103.6\left(\mathrm{C}_{\text {cym }}\right), 86.0\left(\mathrm{CH}_{\mathrm{cym}}\right), 85.5\left(\mathrm{CH}_{\text {cym }}\right), 84.4$ $\left(\mathrm{CH}_{\text {cym }}\right), 84.2\left(\mathrm{CH}_{\text {cym }}\right), 47.4\left(\mathrm{NCH}_{3}\right), 31.6\left(\mathrm{CHMe}_{2}\right), 22.5\left(\mathrm{cym}-\mathrm{CH}_{3}\right), 22.2\left(\mathrm{CH}-\mathrm{CH}_{3}\right), 19.2\left(\mathrm{CH}-\mathrm{CH}_{3}\right)$. Elem. Anal. Calcd. for $\mathrm{C}_{23} \mathrm{H}_{25} \mathrm{ClF}_{3} \mathrm{~N}_{3} \mathrm{O}_{4} \mathrm{RuS} \times 0.25 \mathrm{Et}_{2} \mathrm{O}: \mathrm{C}, 44.43 ; \mathrm{H}, 4.34 ; \mathrm{N}, 6.39$. Found: C, 44.20; $\mathrm{H}, 4.34 ; \mathrm{N}, 6.25$. HR-MS: $\mathrm{m} / \mathrm{z}$ calculated for $\mathrm{C}_{22} \mathrm{H}_{25} \mathrm{~N}_{3} \mathrm{OClRu}$ [M-OTf] ${ }^{+}=484.0730$; found, 484.0715.

Complex 3c. Compound 2c (116 mg, $0.22 \mathrm{mmol})$, NaOAc (180 mg, $2.2 \mathrm{mmol})$ and $\left[\mathrm{RuCl}_{2}(\mathrm{cym})\right]_{2}(61$ $\mathrm{mg}, 0.1 \mathrm{mmol})$ were dissolved in $\mathrm{CH}_{2} \mathrm{Cl}_{2}(50 \mathrm{~mL})$ The reaction mixture was stirred for $18 \mathrm{~h}$ at $\mathrm{rt}$. All volatiles were removed under reduced pressure and the crude solid was purified by column 
chromatography $\left(\mathrm{SiO}_{2} ; \mathrm{CH}_{2} \mathrm{Cl}_{2} / \mathrm{MeOH}\right.$ 95:5) yielding compound $\mathbf{3 c}$ as a red solid (52 $\mathrm{mg}, 39 \%$ ). Crystals suitable for $\mathrm{X}$-ray diffraction analysis were grown by slow evaporation of a $\mathrm{CH}_{2} \mathrm{Cl}_{2}$ solution of complex 3c. Despite the crystallinity of the material and the spectral purity (NMR, HR-MS), we were unable to get microanalytical data with correct $\mathrm{N} \%$.

${ }^{1} \mathrm{H}$ NMR $\left(300 \mathrm{MHz}, \mathrm{CD}_{2} \mathrm{Cl}_{2}\right): \delta 9.04\left(\mathrm{~d},{ }^{3} J_{\mathrm{HH}}=7.7 \mathrm{~Hz}, 1 \mathrm{H}, \mathrm{CH}_{\mathrm{pyr}}\right), 8.68\left(\mathrm{~d},{ }^{3} J_{\mathrm{HH}}=7.2 \mathrm{~Hz}, 2 \mathrm{H}, \mathrm{CH}_{\mathrm{PYA}}\right)$, $8.15\left(\mathrm{~d},{ }^{3} J_{\mathrm{HH}}=7.2 \mathrm{~Hz}, 2 \mathrm{H}, \mathrm{CH}_{\mathrm{PYA}}\right), 8.00\left(\mathrm{~d},{ }^{3} J_{\mathrm{HH}}=5.8 \mathrm{~Hz}, 1 \mathrm{H}, \mathrm{CH}_{\mathrm{pyr}}\right), 7.55\left(\mathrm{dd},{ }^{3} J_{\mathrm{HH}}=7.7 \mathrm{~Hz},{ }^{3} J_{\mathrm{HH}}=\right.$ $\left.5.8 \mathrm{~Hz}, 1 \mathrm{H}, \mathrm{CH}_{\mathrm{pyr}}\right), 5.41-5.33$ (m, overlapped with $\mathrm{CDHCl}_{2}$ signal, $\left.2 \mathrm{H}, \mathrm{CH}_{\mathrm{cym}}\right), 5.24\left(\mathrm{~d},{ }^{3} J_{\mathrm{HH}}=6.0 \mathrm{~Hz}\right.$, $\left.1 \mathrm{H}, \mathrm{CH}_{\mathrm{cym}}\right), 5.12\left(\mathrm{~d},{ }^{3} J_{\mathrm{HH}}=6.0 \mathrm{~Hz}, 1 \mathrm{H}, \mathrm{CH}_{\mathrm{cym}}\right), 4.52\left(\mathrm{~s}, 3 \mathrm{H}, \mathrm{N}_{\mathrm{pyr}} \mathrm{CH}_{3}\right), 4.17\left(\mathrm{~s}, 3 \mathrm{H}, \mathrm{N}_{\mathrm{PYA}} \mathrm{CH}_{3}\right), 2.36$ (septet, $\left.{ }^{3} \mathrm{~J}_{\mathrm{HH}}=6.9 \mathrm{~Hz}, 2 \mathrm{H}, \mathrm{CHMe}_{2}\right), 2.04\left(\mathrm{~s}, 3 \mathrm{H}, \mathrm{cym}-\mathrm{CH}_{3}\right), 1.02\left(\mathrm{~d},{ }^{3} \mathrm{~J}_{\mathrm{HH}}=6.9 \mathrm{~Hz}, 3 \mathrm{H}, \mathrm{CH}-\mathrm{CH}_{3}\right), 1.01$ $\left(\mathrm{d},{ }^{3} J_{\mathrm{HH}}=6.9 \mathrm{~Hz}, 3 \mathrm{H}, \mathrm{CH}-\mathrm{CH}_{3}\right) .{ }^{13} \mathrm{C}$ NMR $\left(100 \mathrm{MHz}, \mathrm{CD}_{2} \mathrm{Cl}_{2}\right): \delta 183.6\left(\mathrm{C}_{\text {carbene }}\right), 170.9(\mathrm{CO}), 168.4$ (C $\left.\mathrm{CPYA}_{\mathrm{PA}}\right), 158.1\left(\mathrm{CH}_{\mathrm{pyr}}\right), 147.4\left(\mathrm{C}_{\mathrm{pyr}}\right), 143.1\left(\mathrm{CH}_{\mathrm{PYA}}\right), 141.8\left(\mathrm{CH}_{\mathrm{pyr}}\right), 125.3\left(\mathrm{CH}_{\mathrm{pyr}}\right), 124.2\left(\mathrm{CH}_{\mathrm{PYA}}\right), 102.1$ $\left(\mathrm{C}_{\text {cym }}\right), 101.4\left(\mathrm{C}_{\text {cym }}\right), 92.4\left(\mathrm{CH}_{\text {cym }}\right), 88.9\left(\mathrm{CH}_{\text {cym }}\right), 86.3\left(\mathrm{CH}_{\text {cym }}\right), 85.9\left(\mathrm{CH}_{\text {cym }}\right), 47.3\left(\mathrm{NCH}_{3}\right), 47.0\left(\mathrm{NCH}_{3}\right)$, $31.5\left(\mathrm{CHMe}_{2}\right), 23.0\left(\mathrm{cym}-\mathrm{CH}_{3}\right), 21.9\left(\mathrm{CH}-\mathrm{CH}_{3}\right), 18.9\left(\mathrm{CH}-\mathrm{CH}_{3}\right)$. Elem. Anal. Calcd. for $\mathrm{C}_{24} \mathrm{H}_{27} \mathrm{ClF}_{3} \mathrm{~N}_{3} \mathrm{O}_{4} \mathrm{RuS}$ : C, 44.55; H, 4.21; N, 6.49. Found: C, 44.24; H, 4.43; N, 5.78. HR-MS: m/z calculated for $\mathrm{C}_{23} \mathrm{H}_{27} \mathrm{~N}_{3} \mathrm{OClRu}[\mathrm{M}-\mathrm{OTf}]^{+}=498.0881$; found, 498.0896 .

General procedure for base-assisted catalytic transfer hydrogenation. In a one neck-round bottom flask, a mixture of catalyst precursor $(0.01 \mathrm{mmol})$, hexamethylbenzene $(27 \mathrm{mg}, 0.16 \mathrm{mmol})$ as internal standard and $\mathrm{KOH}\left(2 \mathrm{M}\right.$ solution in $\left.\mathrm{H}_{2} \mathrm{O}, 50 \mu \mathrm{L}, 0.1 \mathrm{mmol}\right)$ in $i \operatorname{PrOH}(5 \mathrm{~mL})$ was heated to reflux for 15 min. Then, substrate $(1.0 \mathrm{mmol})$ was rapidly added and aliquots $(\mathrm{ca} .0 .1 \mathrm{~mL})$ were taken at set times and dissolved in $\mathrm{CDCl}_{3}$. The reaction mixtures were analysed by ${ }^{1} \mathrm{H}$ NMR spectroscopy. Conversions and yields were determined relative to hexamethylbenzene.

Electrochemistry. Electrochemical measurements were carried out by using an EG\&G Princeton Applied Research potentiostat model 273A typically at a $400 \mathrm{mVs}^{-1}$ sweep rate employing a gastight three-electrode cell under an argon atmosphere. A Pt disk with a $3.80 \mathrm{~mm}^{2}$ surface area was used as the working electrode and was polished before each measurement. The reference electrode was a $\mathrm{Ag} / \mathrm{AgCl}$ electrode; the counter electrode was a Pt wire. $\mathrm{Bu}_{4} \mathrm{NPF}_{6}(0.1 \mathrm{M})$ in dry $\mathrm{CH}_{2} \mathrm{Cl}_{2}$ was used as a base electrolyte with analyte concentrations of approximately $10^{-3} \mathrm{M}$. The ferrocenium/ferrocene redox couple was used as an internal reference $\left(E_{1 / 2}=+0.46 \mathrm{~V}\right.$ vs. SCE in $\left.\mathrm{CH}_{2} \mathrm{Cl}_{2}\right){ }^{18}$

Crystal structure determinations. Suitable crystals of $\mathbf{3 a}, \mathbf{3 b}$, and $\mathbf{3 c}$ were mounted in air at ambient conditions and measured on an Oxford Diffraction SuperNova area-detector diffractometer at T $=173(2)$ K using mirror optics monochromated Mo Ka radiation $(\lambda=0.71073 \AA)$ and Al filtered. ${ }^{19}$ Data reduction was performed using the CrysAlisPro program. ${ }^{19}$ The intensities were corrected for Lorentz and polarization effects, and an absorption correction based on the multi-scan method using SCALE3 
ABSPACK in CrysAlisPro was applied. ${ }^{20}$ The structures were solved by direct methods using SHELXT, ${ }^{21}$ and all non-hydrogen atoms were refined anisotropically. All H-atoms were placed in geometrically calculated positions and refined using a riding model with each $\mathrm{H}$-atom assigned a fixed isotropic displacement parameter (1.2Ueq of its parent atom, 1.5Ueq for the methyl groups). Structures were refined on $F^{2}$ using full-matrix least-squares procedures. The weighting schemes were based on counting statistics and included a factor to downweight the intense reflections. All calculations were performed using the SHELXL-2014 program. $^{21}$

The crystal of 3a contained a molecule of co-crystallized $\mathrm{H}_{2} \mathrm{O}$ (disordered over two sites). The asymmetric unit of $\mathbf{3 b}$ contained one complex molecule, one triflate anion and one disordered solvent molecule. The geometries of the disordered moieties were restrained to be similar. The ADP's of the disordered moieties were restrained by SHELX SIMU and DELU instructions. All studied crystals of 3c contained disordered solvent molecules that however could not be perfectly localized and modelled. For this reason, the routine SQUEEZE was used to remove solvent contribution from the observed structure factors and refine a solvent free model. Further details are given in Tables S1-S3. Crystallographic data for all three structures have been deposited with the Cambridge Crystallographic Data Centre (CCDC) as supplementary publication numbers 1989987 (3a), 1989988 (3b), and 1989989 (3c).

Acknowledgements. We acknowledge generous financial support from the European Research Council (CoG 615653) and from the Swiss National Science Foundation (200021_162868 and 20021_182663, R'equip projects 206021_128724 and 206021_170755). We thank the group of Chemical Crystallography of the University of Bern for the X-ray analysis of all reported structures.

Supporting Information. Catalytic, crystallographic, and electrochemical details, and NMR spectra of all compounds.

Declaration of competing financial interests: The authors declare no competing financial interests.

\section{References}

1. a) Hahn, F. E.; Jahnke, M. C. Heterocyclic Carbenes: Synthesis and Coordination Chemistry. Angew. Chem. Int. Ed. 2008, 47, 3122-3172; b) Arduengo, A. J.; Bertrand, G. Carbenes Introduction. Chem. Rev. 2009, 109, 3209-3210; c) Melaimi, M.; Soleilhavoup, M.; Bertrand, G. Stable Cyclic Carbenes and Related Species beyond Diaminocarbenes. Angew. Chem. Int. Ed. 2010, 49, 8810-8849; d) Albrecht, M. Normal and Abnormal N-Heterocyclic Carbene Ligands: Similarities and Differences of Mesoionic C-Donor Complexes. Adv. Organomet. Chem. 2014, 62, 111-159; e) Schuster, O.; Yang, L.; Raubenheimer, H. G.; Albrecht, M. Beyond Conventional N-Heterocyclic Carbenes: Abnormal, Remote, and Other Classes of 
NHC Ligands with Reduced Heteroatom Stabilization. Chem. Rev. 2009, 109, 3445-3478; f) Donnelly, K. F.; Petronilho, A.; Albrecht, M. Application of 1,2,3-Triazolylidenes as Versatile NHC-type Ligands: Synthesis Properties, and Application in Catalysis and Beyond. Chem. Commun. 2013, 49, 1145-1159; g) Back, O.; Henry-Ellinger, M.; Martin, C. D.; Bertrand, G. ${ }^{31} \mathrm{P}$ NMR Chemical Shifts of Carbene-Phosphinidene Adducts as Indicator of the $\pi$-Accepting Properties of Carbenes. Angew. Chem. Int. Ed. 2013, 52, 2939-2943; h) Vummaleti, S. V. C.; Nelson, D. J.; Poater, A.; Gómez-Suárez, A.; Cordes, D. B.; Slawin, A. M. Z.; Nolan, S. P.; Cavallo, L. What can NMR Spectroscopy of Selenoureas and Phosphinidenes Teach us about the $\pi$-Accepting Abilities of N-Heterocyclic Carbenes? Chem. Sci. 2015, 6, 1895-1904; i) Jacobsen, H.; Correa, A.; Poater, A.; Costabile, C.; Cavallo, L. Understanding the M-(NHC) $(\mathrm{NHC}=\mathrm{N}-H e t e r o c y c l i c$ Carbenes) bond. Coord. Chem. Rev. 2009, 253, 687-703.

2. a) Doster, M. E.; Johnson, S. A. Selective $\mathrm{C}=\mathrm{F}$ Bond Activation of Tetrafluorobenzenes by Nickel(0) with a Nitrogen Analogous to N-Heterocyclic Carbenes. Angew. Chem. Int. Ed. 2009, 48, 2185-2187; b) Doster, M. E.; Hatnean, J. A.; Jeftic, T.; Modi, S.; Johnson, S. A. Catalytic C-H Bond Stannylation: A New Regioselective Pathway to C-Sn Bonds via Ch-H Bond Functionalization. J. Am. Chem. Soc. 2010, 132, 11923-11925; c) Doster, M. E.; Johnson, S. A. Carbon-Hydrogen Bond Stannylation and Alkylation Catalyzed by Nitrogen-DonorSupported Nickel Complexes: Intermediates with $\mathrm{Ni}-\mathrm{Sn}$ Bonds and Catalytic Carbostannylation Ethylene with Organostannanes. Organometallics, 2013, 32, 4174-4184; d) Shi, Q.; Thatcher, R. J.; Slattery, J.; Sauari, P. S.; Whitwood, A. C.; McGowan, P. C.; Douthwaite, R. E. Synthesis, Coordination Chemistry and Bonding of Strong N-Donor Ligands Incorporating the 1H-Pyridine-(2E)-ylidene (PYE) Motif. Chem. Eur. J. 2009, 15, 1134611360; e) Slattery, J.; Thatcher, R. J.; Shi, Q.; Douthwaite, R. E. Comparison of Donor Properties of N-Heterocyclic Carbenes and N-donors Containing the $1 H$-Pyridin-(2E)-lyidene Motif. Pure Appl. Chem. 2010, 82, 1663-1671; f) Thatcher, R. J.; Johnson, D. G.; Slattery, J. M.; Douthwaite, R. E. Charged Behaviour from Neutral Ligands: Synthesis and Properties of N-Heterocyclic Pseudo-amides. Chem. Eur. J. 2012, 18, 4329-4336.

3. a) Leigh, V.; Carleton, D. J.; Olguin, J.; Mueller-Bunz, H.; Wright, L. J.; Albrecht, M. SolventDependent Switch of Ligand Donor Ability and Catalytic Activity of Ruthenium(II) Complexes Containing Pyridinylidene Amide (PYA) N-Heterocylic Carbene Hybrid Ligands. Inorg. Chem. 2014, 53, 8054-8060; b) Donnelly, K. F.; Segarra, C.; Shao, L-X.; Suen, Rachelle, MüllerBunz, H.; Albrecht, M. Adaptive N-Mesoionic Ligands Anchored to a Triazolylidene for Ruthenium-Mediated (De)Hydrogenation Catalysis. Organometallics 2015, 34, 4076-4068; c) Melle, P.; Manoharan, Y.; Albrecht, M. Modular Pincer-type Pyridylidene Amide Ruthenium(II) Complexes for Efficient Transfer Hydrogenation Catalysis. Inorg. Chem. 2018, $57,11761-11774$. 
4. Salzmann, K.; Segarra, C.; Albrecht, M. Donor-Flexible bis-Pyridine Amide Ligands for Highly Efficient Ruthenium-Catalyzed Olefin Oxidation. Angew. Chem. Int. Ed. 2020, DOI: 10.1002/anie.202002014.

5. a) Navarro, M.; Li, M.; Müller-Bunz, H.; Bernhard, S.; Albrecht, M. Donor-Flexible Nitrogen Ligands for Efficient Iridium-Catalyzed Water Oxidation Catalysis. Chem. Eur. J. 2016, 22 , 6740-6745; b) Navarro, M.; Smith, C. A.; Albrecht, M. Enhanced Catalytic Activity of Iridium(III) Complexes by Facile Modification of C,N-Bidentate Chelating Pyridylideneamide Ligands. Inorg. Chem. 2017, 56, 11688-11701; c) Navarro, M.; Li, M.; Bernhard, S.; Albrecht, M. A Mesoionic Nitrogen-Donor Ligand: Structure, Iridium Coordination, and Catalytic Effects. Dalton Trans. 2018, 47, 659-662; d) Navarro, M.; Smith, C. A.; Li, M.; Bernhard, S.; Albrecht, M. Optimization of Synthetically Versatile Pyridylidene Amide Ligands for Efficient Iridium-Catalyzed Water Oxidation. Chem. Eur. J. 2018, 24, 6386-6398.

6. Lundgren, R. J.; Stradiotto, M. Ligand Design in Metal Chemistry: Reactivity and Catalysis. John Wiley \& Sons: Chichester, UK, 2016.

7. van Dijk, T.; Burck, S.; Rong, M. K.; Rosenthal, A. J.; Nieger, M.; Slootweg, J. C.; Lammertsma, K. Facile Synthesis of Phosphaamidines and Phosphaamidinates Using Nitrilium Ions as an Imine Synthon. Angew. Chem. Int. Ed. 2014, 53, 9068-9071.

8. a) Davies, D. L.; Donald, S. M. A.; Macgregor, S. A. Computational Study of the Mechanism of Cyclometalation by Palladium Acetate. J. Am. Chem. Soc. 2005, 127, 13754-13755; b) Davies, D. L.; Donald, S. M. A.; Al-Duaij, O.; Fawcett, J.; Little, C.; Macgregor, S. A. N-H versus $\mathrm{C}-\mathrm{H}$ Activation of a Pyrrole Imine at $\{\mathrm{Cp} * \mathrm{Ir}\}$ : A Computational and Experimental Study. Organometallics 2006, 25, 5976-5978; c) Albrecht. M. Cyclometalation Using d-Block Transition Metals: Fundamental Aspects and Recent Trends. Chem. Rev. 2010, 110, 576-623.

9. a) Mishra, A.; Kaushik, N. K.; Verma, A. K.; Gupta, R. Synthesis, Characterization and Antibacterial Activity of Cobalt(III) Complexes with Pyridine-Amide Ligands. Eur. J. Med. Chem. 2008, 43, 2189-2196; b) Kumar, P.; Gupta, R. The Wonderful World of Pyridine-2,6dicarboxamide Based Scaffolds. Dalton Trans. 2016, 45, 18769-18733.

10. a) Boyd, P. D. W.; Wright, L. J.; Zafar, M. N. Extending the Range of Neutral N-Donor Ligands Available for Metal Catalysts: $N$-[1-Alkylpyridin-4(1H)-ylidene]amides in PalladiumCatalyzed Cross-Coupling Reactions. Inorg. Chem. 2011, 50, 10522-10524; b) Muller, C. M. A.; Babak, M. V.; Kubanik, M.; Hanif, M.; Jamieson, S. M. F.; Hartinger, C. G.; Wright, L. J. $\mathrm{Pt}(\mathrm{II})$ pyridinium amidate (PYA) Complexes: Preparation and in vitro Anticancer Activity Studies. Inorg. Chim. Acta. 2016, 450, 124-130; c) Navarro, M.; Rosar, V. Montini, T.; Milani, B.; Albrecht. M. Olefin Dimerization and Isomerization Catalyzed by Pyridylidene Amide Palladium Complexes. Organometallics 2019, 37, 3619-3630.

11. Isobe, K.; Kai, E.; Nakamura, Y.; Nishimoto, K.; Miwa, T.; Kawaguchi, S.; Kinoshita, K.; Nakatsu, K. Trans-Bromo(2-,3-, and 4-Pyridyl)bis(Triethylphosphine)Palladium(II) 
Complexes. J. Am. Chem. Soc. 1980, 102, 2475-2476.

12. Balcells, D.; Clot, E.; Eisenstein, O. C-H Bond Activation in Transition Metal Species from a Computational Perspective. Chem. Rev.2010, 110, 749-823.

13. For complex 3d, the presence of two PYA derived from an oxalamide core allows for more twisting than the (hetero)arylamide core. Therefore, the values from one PYA moieties differ significantly.

14. Abbotto, A.; Bradamante, S.; Pagani, G.A. Pyridoneimines and Pyridonemethides: Substituentand Solvent-Tunable Intramolecular Charge Transfer and Geometric Isomerism. J. Org. Chem. 2001, 66, 8883-8892.

15. a) Zassinovich, G.; Mestroni, G.; Gladiali, S. Asymmetric Hydrogen Transfer Reactions Promoted by Homogeneous Transition Metal Catalyst. Chem. Rev. 1992, 92, 1051-1069; b) Klomp, D.; Hanefeld, U.; Peters, J. A. in The Handbook of Homogeneous Hydrogenation; de Vries, J. G., Elsevier, C. J. Eds.; Wiley-VCH: Weinheim, Germany, 2007; p585; c) Samec, J. S. M.; Bäcvall, J-E.; Anderson, P. G.; Brandt, P. Mechanistic Aspects of Transition MetalCatalyzed Hydrogen Transfer Reactions. Chem. Soc. Rev. 2006, 35, 237-248; d) Wang, D.; Astruc, D. The Golden Age of Transfer Hydrogenation Chem. Rev. 2015, 115, 6621-6686; e) Wang, C.; Pettman, A.; Bacsa, J.; Xiao, J. A Versatile Catalyst for Reductive Amination by Transfer Hydrogenation. Angew. Chem. Int. Ed. 2010, 49, 7548-7552; f) Talwar, D.; Wu, X.; Saidi, O.; Poyatos-Salguero, N.; Xiao, J. Versatile Iridicyle Catalyst for Highly Efficient and Chemoselective Transfer Hydrogenation of Carbonyl Compounds in Water. Chem. Eur. J. 2014, 20, 12835-12842; g) Wei, Y.; Xue, D.; Lei, Q.; Wang, C.; Xiao, J. Cyclometalated Iridium Complexes for Transfer Hydrogenation of Carbonyl Groups in Water. Green Chem. 2013, 15, 629-634.

16. a) Delgado-Rebollo, M.; Canseco-Gonzalez, D.; Hollering, M.; Mueller-Bunz, H.; Albrecht, M. Synthesis and Catalytic Alcohol Oxidation and Ketone Transfer Hydrogenation of DonorFunctionalized Mesoionic Triazolylidene Ruthenium(II) Complexes. Dalton Trans. 2014, 43, 4462-4473; b) Vivancos, A.; Albrecht, M. Influence of the Linker Length and Coordination Mode of (Di)Triazolylidene Ligands on the Structure and Catalytic Transfer Hydrogenation Activity of Iridium(III) Centers. Organometallics, 2017, 36, 1580-1590; c) Farrell, K.; MüllerBunz, H.; Albrecht, M. Synthesis, Isomerization, and Catalytic Transfer Hydrogenation Activity of Rhodium(III) Complexes Containing Both Chelating Dicarbenes and Diphosphine Ligands. Organometallics 2015, 34, 5723-5733; d) Pretorius, R.; Mazloomi, Z.; Albrecht, M. Synthesis, Hemilability, and Catalytic Transfer Hydrogenation Activity of Iridium(III) and Ruthenium(II) Complexes Containing Oxygen-Functionalised Triazolylidene Ligands. J. Organomet. Chem. 2017, 845, 196-205.

17. a) Chai, H. N.; Wang, Q. F.; Liu, T. T.; Yu, Z. K. Diruthenium(II)-NNN Pincer Complex Catalysts for Transfer Hydrogenation of Ketones. Dalton Trans. 2016, 45, 17843-17849; b) 
Zhu, X.-H.; Cai, L.-H.; Wang, C.-X.; Wang, Y.-N.; Guo, X.-Q.; Hou, X.-F. Efficient and Versatile Transfer Hydrogenation Catalysts: Iridium (III) and Ruthenium (II) Complexes with 4-Acetylbenzyl N-Heterocyclic Carbenes. J. Mol. Catal. A: Chem. 2014, 393, 134-141; c) Liu, T. T.; Chai, H. N.; Wang, L.; Yu, Z. K. Exceptionally Active Assembled Dinuclear Ruthenium(II)-NNN Complex Catalysts for Transfer Hydrogenation of Ketones. Organometallics 2017, 36, 2914-2921; d) Zeng, F. L.; Yu, Z. K. Construction of Highly Active Ruthenium(II) NNN Complex Catalysts Bearing a Pyridyl-Supported Pyrazolyl-Imidazolyl Ligand for Transfer Hydrogenation of Ketones. Organometallics 2009, 28, 1855-1862.

18. Connelly, N. G.; Geiger, W. E. Chemical Redox Agents for Organometallic Chemistry. Chem. Rev. 1996, 96, 877-910

19. Macchi, P.; Bürgi, H. B.; Chimpri, A. S.; Hauser, J.; Gal, Z. Low-energy contamination of Mo microsource X-ray radiation: analysis and solution of the problem. J. Appl. Cryst, 2011, 44, 763-771.

20. Oxford Diffraction (2010). CrysAlisPro (Version 1.171.34.44). Oxford Diffraction Ltd., Yarnton, Oxfordshire, UK.

21. Sheldrick, G. M. SHELXT - Integrated space-group and crystal structure determination. Acta Cryst. 2015, $A 71,3-8$. 